\title{
Las colocaciones tipo venirle en voluntad: un patrón construccional desaparecido
}

\author{
Josep Alba-Salas ${ }^{1}$ \\ College of the Holy Cross, Estados Unidos
}

\begin{abstract}
Resumen
Las colocaciones tipo venirle en voluntad, un patrón construccional que parecía productivo en el Medievo, cayeron en desuso y se lexicalizaron en el Siglo de Oro, dejándonos solo reliquias fosilizadas como venirle en gana(s). La pérdida de este patrón conllevó dos cambios relacionados que se discuten dentro del modelo diacrónico de Traugott y Trousdale (2013): la obsolescencia y construccionalización léxica de un subesquema construccional.

Palabras clave: colocaciones, lexicalización, verbos de movimiento, Gramática de Construcciones, estudio diacrónico.
\end{abstract}

COLLOCATIONS OF THE TYPE VENIRLE EN VOLUNTAD: A LOST

CONSTRUCTIONAL PATTERN

\begin{abstract}
Collocations of the type venirle en voluntad, a constructional pattern that seemed to be productive in the Middle Ages, fell out of use and became lexicalized in the Golden Age, leaving behind only fossilized relics such as venirle en gana(s). The loss of this pattern involved two related changes that are discussed within Traugott and
\end{abstract}


Trousdale's (2013) diachronic model: the obsolescence and lexical constructionalization of a constructional subschema.

Keywords: collocations, lexicalization, motion verbs, Construction Grammar, diachronic study.

Recibido: 03/06/19 Aceptado: 16/08/19

\section{INTRODUCCIÓN ${ }^{2}$}

Este estudio examina ciertas estructuras del español medieval y del Siglo de Oro que solo nos han dejado vestigios lexicalizados como venirle en gana(s). Dichas estructuras se formaban con venir y, ocasionalmente, entrar y caer más sustantivos que indican algún tipo de 'intención' o 'deseo', como deseo, propósito, voluntad, pensamiento (entendido como 'propósito o intención', cf. $D E A$ y $D R A E$, s.v. pensamiento) y corazón (en su sentido antiguo de 'pensamiento o intención'; cf. DEA y DRAE, s.v. corazón $\left.{ }^{3}\right)$.

(1) En esto, [...], a él le vino en voluntad y deseo de hacer lo que otro no pudiera hacer por él [...]. (Don Quijote, Miguel de Cervantes, 1605) ${ }^{4}$

(2) Vínoli adesoras al rey en coraçón de dar el monesterio al precioso barón, [...]. (Vida de Santo Domingo de Silos, Gonzalo de Berceo, compuesto 1230-1236, copiado 1236-1300 a quo [Biblioteca Abadía Silos, 12])

(3) $[\ldots]$ por diuersidad de milagros: entrome mucho en pensamiento de ser religioso: porque me parecia [...]. (Exemplario contra los engaños, anónimo, compuesto 1493 ad quem, copiado 1493 [BNE, INC/1194])

2 Este trabajo se ha enriquecido gracias a los comentarios y sugerencias de los miembros del grupo GRADIA y de dos evaluadores anónimos, cuyas aportaciones se agradecen enormemente.

3 Con esta acepción, el DRAE (s.v. corazón) aún recoge dos "loc[uciones] verb[ales] desus[adas]": venir en corazón ('desear'), y haber/tener a corazón ('tener propósito o firme resolución de hacer algo').

4 Todos los ejemplos en español citados en este trabajo proceden del CORDE, excepto aquellos donde se indica que proceden del Corpus del español o CdE. Los ejemplos de textos manuscritos del Medievo incluyen tanto la fecha de composición original, como la de copia, obtenidas de PhiloBiblion y el CORDEMÁFORO de Rodríguez Molina y Octavio de Toledo (2017). 
Como podemos ver, el nombre de 'intención' o 'deseo' $\left(N_{\text {intenc/deseo }}\right)$ aparece en un sintagma preposicional encabezado por en, aunque en algunos casos también encontramos $a(4)^{5}$. Dicho nombre suele aparecer desnudo, pero algunos sustantivos pueden llevar artículo $(5)^{6}$. Por otra parte, quien siente la 'intención' o el 'deseo' - esto es, el experimentador- corresponde a un clítico dativo que aparece ocasionalmente con un sintagma correferente introducido por $a$, como en (1) o (2) 7 . Sin embargo, a veces encontramos el sintagma que actúa como complemento indirecto sin el clítico $(6)^{8}$.

(4) [...], e vínole un día a coraçón de ir buscar sus aventuras por que él se podiesse partir del mal de la reina. (Tristán de Leonís, anónimo, 1501)

(5) $[\ldots] \&$ para ser contra los enemigos dela fe: entrole en la voluntad de darle a su hija la heredera por muger que bien vio que [...]. (Gran conquista de Ultramar, anónimo, compuesto 1293, copiado 1503 [BNE, R/518]) [CdE]

5 El uso de en y a reflejaría una alternancia preposicional que se mantuvo con los verbos de movimiento hasta el Siglo de Oro (Martínez García 2012, Morera Pérez 1988: 130). Cabe añadir que, de las 17 combinaciones documentadas en nuestro estudio (véase $\S$ 2), diez aparecen solo con en (venirle en apetito/deseo/gana(s), entrarle en corazón/gana(s)/ pensamiento/voluntad y caerle en gana/pensamiento/voluntad), dos se atestiguan únicamente con $a$, pero en una sola ocurrencia cada una (venirle al ánimo/propósito), y cinco, con ambas preposiciones: venirle más gusto, mente y voluntad (con las que predomina en), y venirle más corazón y pensamiento (con las que $a$ es mayoritaria).

6 De las 17 combinaciones documentadas (cf. § 2), siete aparecen siempre sin artículo (venirle en apetito/deseo/gana(s), caerle en gana/voluntad y entrarle en gana(s)/pensamiento), dos, solo con artículo (venirle al ánimo/propósito, que suman únicamente dos ocurrencias en total), y ocho combinaciones, con o sin él: venirle en/al corazón, venirle en/al gusto, venirle en/a (la) mente y venirle en/a (la) voluntad (con las que hay más casos sin artículo), venirle en/al pensamiento y entrarle en (el) corazón (con las que predomina el artículo), y caerle en (el) pensamiento y entrarle en (la) voluntad (con las que hay un empate de ocurrencias). En general, el artículo suele ser mucho más frecuente con la preposición $a$.

7 En el español medieval el uso de un clítico correferente con un sintagma nominal o un pronombre tónico era infrecuente, y se limitaba a objetos indirectos con función de tópico, pero tal restricción desapareció en el Siglo de Oro al gramaticalizarse la reduplicación del clítico, empezando al parecer con predicados de actividad mental (véanse Melis 2018: 105-120 y las referencias allí citadas). En nuestro estudio, solo tres de las 92 ocurrencias documentadas en textos compuestos entre el XIII y finales del XV incluyen un clítico correferente con un objeto indirecto; dos corresponden a un elemento dislocado a la izquierda, y en el tercero -el ejemplo (2)- la reduplicación del clítico parece obedecer a cuestiones métricas.

8 Hay algunos casos de laísmo con venir, p. ej. (21). Además, ocasionalmente también encontramos algunos ejemplos donde venir, entrar o caer aparecen con un pronombre reflexivo, p. ej. (27). 
(6) Ca aueno asi como plugo a dios / que entro al enperador en voluntad de yr en rromeria como [...]. (Emperatriz de Roma, anónimo, compuesto 1300-1325, copiado 1391-1500 [Esc., h.I.13]) [CdE]

En su forma inicial, la estructura incluía un infinitivo precedido por de, aunque desde mediados del XVI (sobre todo tras el primer cuarto del XVII) encontramos el infinitivo también sin de, como en (7) 9 . Dicho infinitivo quedaba implícito cuando la expresión aparecía en una cláusula subordinada adverbial introducida por como o cuando (8), entre otras conjunciones, o en una cláusula de relativo, típicamente con lo que (9) ${ }^{10}$.

(7) $[\ldots]$ y como $[\ldots]$ la theorica sea casi un vano inutil studio sin la platica, vinome en voluntad traduzir en castellano esta obra y embiarla a Va Sa porque [...]. (Mechánica de Aristóteles, trad. Diego Hurtado de Mendoza, 1545)

(8) $[\ldots]$, deseando verme con mi ganado [...], y bolverme con él a la aldea quando a la voluntad me veniera. (Coloquios satíricos, Antonio de Torquemada, 1553)

(9) [...], ansi a los prinçipes son mucho necçessarios, porque algunas vezes non fagan todo lo que les viene en desseo. (Libro de amor e amicicia, El Tostado, compuesto 1436-1437, copiado 1491-1500 [BUSalamanca, 2178])

Antes de lexicalizarse, las estructuras que nos ocupan (prototípicamente, venirle en $N_{\text {intencldeseo }}$, de + 'infinitivo) tenían un sentido composicional de naturaleza ingresiva o incoativa ${ }^{11}$. Concretamente, su sentido era el de 'empezar a sentir $N_{\text {intencldeseo }}$, de + infinitivo', aunque la paráfrasis más natural en el español moderno sería 'ocurrírsele + infinitivo'. Tales estructuras

$9 \quad$ El uso de de como marca del infinitivo sujeto era común en el español medieval, sobre todo con plazer, pesar, ploguer, convenir y ser menester (Cano Aguilar 1977, Granvik 2007, Martínez García 2012).

10 Raramente, en lugar de un infinitivo encontramos una cláusula finita cuyo sujeto es correferente con el de venir/entrar/caer, p. ej. "si despues uos uiniere a uoluntad que uos querades de mi uengar; fazet me lo saber antes". (Estoria de España II, Alfonso X, comp. 1270-1284, cop. 1284-1360 [Escorial, X-I-4])

11 Como subraya De Miguel (1999: 3023-3025), ingresivo e incoativo no son términos sinónimos: aunque ambos indican un cambio de estado, los predicados ingresivos enfocan la fase inicial de un evento, mientras que los incoativos pueden enfocar la fase inicial, intermedia o final; en otras palabras, los predicados ingresivos constituyen un subconjunto de los incoativos. Las estructuras que nos ocupan son propiamente ingresivas, pero también podrían analizarse como (el subtipo de) incoativas enfocadas en la fase inicial, de ahí que empleemos ambos términos indistintamente (cf. Alba-Salas 2017). 
constituían una versión ingresiva de las Construcciones con Verbo de Apoyo (CVA) formadas con tener (o, en los textos más antiguos, haber) y los nombres de 'intención' o 'deseo' correspondientes, unas CVA cuyo significado era el de 'sentir $N_{\text {'intenc/deseo }}$ ' de hacer algo', p. ej. (10) y (11) ${ }^{12}$.

(10) Este embajador propuso que como el rey su señor tuviese en voluntad y propósito de ponerse entre el rey y sus hermanos y el rey de Castilla por razón de la guerra, [...]. (Anales de la Corona de Aragón, II, Jerónimo Zurita, 1579)

(11) $[. .$.$] mas pues assi es que atan a coraçon lo aueys de vos conbatir$ comigo, dadme plazo hasta que sea guarido de mis llagas [...]. ( $L a$ demanda del Sancto Grial, anónimo, compuesto 1469 ad quem, copiado 1515 [BL G.,10241])

El sentido ingresivo de las estructuras tipo venirle en $N_{\text {intenc/deseo }}$, se confirma con el uso de dobletes como el que encontramos en el Quijote entre venirle en voluntad de + infinitivo (1) y la estructura 'simple' venirle voluntad de + infinitivo (12), en la que voluntad no lleva preposición, y que constituye una versión ingresiva de la CVA 'simple' venirle voluntad de + infinitivo $\left(\right.$ Alba-Salas 2017) ${ }^{13}$.

(12) [...] en esta jaula le ha venido gana y voluntad de hacer aguas mayores o menores, como suele decirse. (Don Quijote, Miguel de Cervantes, 1605)

Las estructuras tipo venirle en $N_{\text {intencldeseo }}$, representan usos figurados de venir, entrar y caer basados en la idea básica de movimiento asociada con estos tres verbos (cf. Barrajón López 2006: 465-800, Morimoto 2001: 204-214, Paz Afonso 2013, Serradilla Castaño 2011) ${ }^{14}$. Por otra parte, estas estructuras pueden considerarse colocaciones en el sentido de Alonso Ramos (2004: 20-21), a saber, combinaciones léxicamente restringidas de dos unidades: una que el hablante escoge libremente como base de la colocación

12 Como las estructuras tipo venirle en $N_{\text {'intenc/deseo, }}$ esta CVA también solía dejar el infinitivo implícito con lo que, cuando, cuanto, etc., cf. ("8) y (9).

13 Otra prueba del carácter ingresivo de venirle en $N_{\text {'intenc/deseo }}$, es la existencia de una construcción sinónima, pero al parecer no productiva, formada con tomar, de la que solo tenemos un ejemplo: "cuando lo vido ansí tan desemejado [...], tomóle en voluntad de lo llevar preso [...]” (Primaleón, anónimo, 1512).

14 Su base conceptual parece ser la metáfora de la intención o el deseo como un contenedor en el que se tiene ( $\mathrm{y}$ al que por tanto también puede venir, entrar o caer) lo que uno quiere hacer. Al parecer, este esquema conceptual se heredó del latín clásico (véase la nota 22). 
para expresar sus necesidades comunicativas; y otra que dicho hablante selecciona como colocativo de forma parcialmente arbitraria en función de la base para expresar un sentido particular (cf. Bosque 2001: 15-20) ${ }^{15}$. De hecho, las construcciones que nos ocupan incluirían dos colocaciones: una formada por el nombre de 'intención' o 'deseo' (la base) más la preposición en (o, en ciertos casos, a) como colocativo (cf. nota 5); y otra mayor en la que este sintagma preposicional sirve de base y selecciona a venir, entrar o caer como colocativo. En cualquier caso, las estructuras tipo venirle en $N_{\text {intenc/deseo }}$, son Construcciones, esto es, unidades lingüísticas aprendidas y convencionalizadas que asocian una forma con un significado (Goldberg 1995: 4; 2006: 5 $)^{16}$. Más concretamente, y como explicaremos en más detalle en la sección 3, estas estructuras constituyen un subesquema construccional formado por abstracción a partir de distintas combinaciones que siguen un patrón común.

Hasta donde alcanza nuestro conocimiento, no hay estudios diacrónicos centrados exclusivamente en las estructuras tipo venirle en $N_{\text {intenc/deseo }}$, a las que en adelante también nos referiremos como el subesquema intencional o de 'intención'. Sin embargo, estas estructuras se discuten en Alba-Salas (2017), cuyo interés principal es examinar la rivalidad histórica entre tres realizaciones diferentes del experimentador en las colocaciones formadas con venir más sustantivos de estado: como dativo (p. ej. venirle vergüenza a alguien), como sujeto (p. ej. venir alguien en vergüenza), o como locativo metafórico (p. ej. venir vergüenza en alguien). Aunque la discusión sobre el experimentador dativo se enfoca fundamentalmente en la estructura 'simple' venirle $N$, Alba-Salas también discute el uso de venirle en $N$ con tres nombres (deseo, voluntad y gana $(s)$ ), atribuyendo a ambas estructuras el sentido incoativo de 'empezar a sentir $N$ '.

Tomando como punto de partida Alba-Salas (2017), el presente estudio investiga en mayor profundidad las estructuras tipo venirle en $N_{\text {intenc/deseo }}$, con una muestra más amplia de nombres de 'intención' o 'deseo' e incorporando

15 Según Alonso Ramos (2004: 40-48), las colocaciones se distinguen tanto de los sintagmas libres, donde un predicado selecciona sus argumentos atendiendo únicamente a sus propiedades semánticas, como de las expresiones fraseológicas, que carecen de composicionalidad semántica y analizabilidad sintáctica.

16 Escribimos Construcción con mayúscula para distinguir este sentido especializado del uso más general de construcción (en minúscula). Las Construcciones (a) presentan diferentes grados de complejidad y abstracción, (b) incluyen palabras, morfemas, frases idiomáticas y esquemas sintácticos muy generales, y (c) abarcan no solo estructuras cuya forma o significado no es estrictamente predecible a partir de sus componentes, sino también patrones composicionales de uso frecuente (Goldberg 2006: 5). 
también entrar y caer. En contraste con nuestro trabajo anterior, empleamos dos corpus: el CORDE, y el Corpus del español o CdE, cuya versión más reciente incluye no solo el subcorpus de 'Género/ Histórico' del siglo XIII al año 2000 (el único empleado por Alba-Salas 2017), sino también el subcorpus del siglo XXI añadido en 2016: 'Web/Dialectos' ${ }^{17}$. Además, a diferencia de Alba-Salas (2017), seguimos el modelo sobre el cambio diacrónico de Traugott y Trousdale (2013), que discutiremos más adelante.

En las secciones siguientes examinamos la distribución histórica del subesquema intencional en los corpus utilizados (§ 2) y discutimos los dos procesos que habrían determinado la pérdida de dicho subesquema: su lexicalización, entendida -siguiendo a Traugott y Trousdale (2013)- como un subtipo de construccionalización léxica ( $(3)$, y su caída en desuso u obsolescencia (§ 4). Terminamos con nuestras conclusiones $(\S 5)$.

\section{DISTRIBUCIÓN HISTÓRICA}

La búsqueda en el $C O R D E$ y el $C d E$ se centró en doce sustantivos que podrían haberse empleado potencialmente en las estructuras estudiadas y que se documentan por primera vez en los dos corpus (aunque no necesariamente con caer, entrar o venir) en textos compuestos y copiados antes de 1500: ánimo, apetito/apetencia (en su uso antiguo como 'deseo'; cfr. DEA y DRAE, s.v. apetencia y apetito), corazón (en el sentido antiguo de 'pensamiento o intención' que ya hemos mencionado), deseo, gana(s) ${ }^{18}$, gusto (no como 'agrado o placer', sino como 'voluntad o deseo'; DEA, s.v. gusto ${ }^{19}$ ), impulso,

17 'Web/Dialectos' comprende más de dos mil millones de palabras procedentes de blogs y páginas de internet de veintiún países hispanohablantes, incluyendo Estados Unidos. Se empleó este subcorpus para el siglo XXI porque es mucho mayor que los de la RAE, una consideración importante para el estudio de estructuras poco frecuentes. Esta misma consideración explica por qué se empleó tanto el $C d E$ como el $C O R D E$ para los siglos anteriores: aunque este es mucho mayor y documenta las estructuras analizadas en textos que no aparecen en aquel, el $C d E$ incluye ejemplos que no se recogen en el $C O R D E$.

18 En los corpus empleados, gana(s) aparece solo en singular con caer, pero con entrar y sobre todo venir (especialmente en el siglo XXI) también encontramos algunas ocurrencias en plural. Se trata de una palabra "de origen incierto" (derivada tal vez del gótico *GANÔ 'gana, avidez') y "propia del castellano y el catalán” (DCECH, s. v. gana).

19 Alba-Salas (2019 y 2020) discute el uso de gusto como 'agrado o placer' en otras Construcciones. 
intención, mente (en su acepción anticuada de 'intención o voluntad'; cf. $D E A$ y DRAE, s.v. mente ${ }^{20}$, pensamiento (siempre como 'propósito o intención'), propósito y voluntad (en su sentido de 'intención, ánimo o resolución de hacer algo', $D R A E$, s.v. voluntad). Se buscó tanto la forma moderna de los nombres y verbos en cuestión como sus variantes históricas y ortográficas.

Combinados, y excluyendo los casos repetidos, el CORDE y el $C d E$ incluyen un total de 1594 ocurrencias relevantes. De estas, 1344 son de venirle en gana(s) (cf. nota 18), y 250 pertenecen a las combinaciones restantes. Las combinaciones documentadas con cada verbo aparecen en (13), con el número de casos entre paréntesis (cf. notas 5 y 6). Como podemos ver, venir -atestiguado con diez nombres en 1566 ocurrencias-es claramente el verbo prototípico en estas estructuras. Por otra parte, entrar y caer parecen haber tenido un carácter periférico. En efecto, el primero aparece con cuatro sustantivos en un total de 23 casos, mientras que caer solo tiene un total de cinco ocurrencias con tres sustantivos ${ }^{21}$. Por otra parte, de las combinaciones documentadas al margen de venirle en gana(s), solo ocho parecen haberse empleado con relativa frecuencia: entrarle en gana(s), entrarle en (la) voluntad, venirle en deseo y venirle en (o a la) mente, que tienen entre nueve y dieciocho ocurrencias cada una; y venirle en (o a/al) corazón, venirle en gusto (o al gusto o, en ciertas variedades que discutimos más adelante, de gusto, $\mathrm{cf}$. (33)), venirle en (o al) pensamiento y venirle en (o a) (la) voluntad, que suman entre 29 y 93 casos cada una. Las combinaciones restantes solo tienen entre una y tres ocurrencias, por lo que su uso parece haber sido marginal.

(13) caerle en gana (2) / en (el) pensamiento (2) / en voluntad (1); entrarle en (el) corazón (3) / en gana(s) (9) / en pensamiento (1) / en (la) voluntad (10); venirle al ánimo (1) / en apetito (2) / a(1)/en corazón (29) / en deseo (11) / en gana(s) (1344) / al/en/(de) gusto (30) / a la/en mente (18) / al/en pensamiento (37) / al propósito (1) / a/en (la) voluntad (93)

Además de venirle en gana(s), a la que volveremos más adelante, varias combinaciones merecen atención especial: venirle en (o a la) mente, caerle en

20 Este sentido, atestiguado desde el XVII hasta mediados del XX en textos religiosos, queda claro en ejemplos como "[...] al cardenal de Santa Cruz [...] oyó decir, que esta havía sido la mente de los padres en aquella declaración". (Theatro crítico universal VII, Benito Jerónimo Feijoo, 1736)

21 El predominio de venir obedecería a su mayor arraigo histórico y cognitivo que entrar y caer con experimentadores dativos (en oposición a experimentadores sujeto o locativos) en varias colocaciones con nombre predicativos (véase Alba-Salas 2016a, 2016b, 2017 y 2019). 
(el) pensamiento y venirle en (o al) pensamiento. Como las otras expresiones, estas combinaciones aparecen con el sentido relevante de 'empezar a sentir $N_{\text {intenc/deseo }}$, de hacer algo', esto es, 'ocurrírsele hacer algo', p. ej. (14), y constituían una versión ingresiva de la CVA con tener correspondiente (haber no se documenta), p. ej. (15).

(14) [...], a esta sasón le vino al pensamiento de querer yr estonces a Seuilla. (Novelas en verso, Cristóbal de Tamariz, 1580)

(15) [...], y era tan grande que tenía en pensamiento de ser cavallero cuando Polendos lo fuesse. (Primaleón, anónimo, 1512)

Sin embargo, estas expresiones se atestiguan también (y con mayor frecuencia) con el sentido de 'ocurrírsele una idea', y no 'la intención de hacer algo' (16). Además, venirle al/en pensamiento y sobre todo venirle a la/en mente aparecen con el sentido -en el caso de mente, muchísimo más común hasta el Siglo de Oro- de 'recordar' (17). Aunque estos dos usos también constituyen versiones ingresivas de una CVA con haber o tener - p. ej. tener en pensamiento (una idea) en (18), y haber en mente (un recuerdo) en (19)no pertenecen al subesquema intencional porque no indican la 'intención de hacer algo', y por tanto se excluyen de nuestro análisis cuantitativo ${ }^{22}$.

22 La ambigüedad de estas combinaciones parece obedecer a la polisemia del verbo con el que pensamiento y mente se relacionan semántica y (en el caso de pensamiento) morfológicamente. En efecto, pensar se ha empleado históricamente no solo con el sentido de 'formar o combinar ideas o juicios en la mente' ( $\mathrm{p}$. ej. me asusta lo que pienso) y de 'recordar o traer a la mente algo o a alguien' (p. ej. me esforzaba en no pensar en ella), sino también como 'tener la intención de hacer algo' (p. ej. pienso ir mañana), entre otros usos (DRAE, s.v. pensar). En el caso de mente, los tres usos se remontan al latín clásico y arcaico, donde encontramos in mentem uenire alicui 'venirle en mente a alguien' con el sentido de 'ocurrírsele hacer algo' (i), 'ocurrírsele una idea' (ii), y, sobre todo, 'recordar (algo o a alguien)' (iii) (Glare 1996; ejemplos de Loeb; la traducción es nuestra). Cabe añadir que el latín también tenía ciertas CVA con HABERE 'tener' con el sentido de 'tener la intención de hacer algo', p. ej. in animo habere (iv) (Lewis y Short 1879, s. v. HABEO, acepción G).

(i) Qui in mentem uenit tibi istuc facinus facere tam malum? ¿¿Cómo se te ocurrió cometer un crimen tan horrible como este?' (Bacchides 685, Plauto, s. II a. C.)

(ii) Non tibi venit in mentem, amabo, si dum vivas tibi bene facias tam pol id quidem esse haud perlonginquom [...]? '¿Y no se te ocurre, alma de cántaro, que si te diviertes mientras estás vivo, no va a ser por mucho tiempo [...]?' (Bacchides 1193-1195, Plauto, s. II a. C.)

(iii) Venit enim mihi Platonis in mentem, quem [...]. 'Me acuerdo de Platón, al que [...]'. (de Finibus Bonorum et Malorum 5.2, Cicerón, s. I a. C.)

(iv) "Immo vero," inquit, "est; nam istum exheredare in animo habebat". "Claro que lo hay -dijo-ya que tenía intención de desheredarlo'. (Pro Sexto Roscio Amerino 18.52, Cicerón, s. I a. C.) 
(16) [...]; pero ¿qué haré de rosario, que no le tengo? En esto le vino al pensamiento cómo le haría, y fue que rasgó [...]. (Don Quijote, Miguel de Cervantes, 1605)

(17) Di, Ferrando, otorga esta razón: / ¿non te viene en miente en Valencia lo del león, / cuando durmié mio Cid e el león se desató? (Poema de Mio Cid, anónimo, compuesto 1110-1210 (?), copiado 1325-1330 ca. [BNE, Vitr/7/17])

(18) Porque tengo en pensamiento / que, veniéndome la muerte, / no me puede venir suerte / que me [...]. (Comedia Jacinta, Bartolomé de Torres Naharro, 1517)

(19) $[. .$.$] mi buen fijo, pídote [...] que ayas en miente la muerte de tus$ hermanos, que Archiles mató [...]. (Istoria de las bienandanzas e fortunas, Lope García de Salazar, compuesto 1471-1476 ad quem, copiado 1492 [RAH, 9-10-2/2100])

La Tabla 1 muestra las ocurrencias absolutas por siglo de las diecisiete combinaciones documentadas en las estructuras tipo venirle en $N_{\text {:intencideseo, }}$, distinguiendo la fecha de composición de la fecha de copia ${ }^{23}$. En vista de su estatus especial, presentamos separadamente tanto venirle en gana(s) como venirle a la/en mente, caerle en (el) pensamiento y venirle al/en pensamiento (en su sentido relevante de 'empezar a sentir la intención de hacer algo'). Los Gráficos 1 y 2 muestran las ocurrencias por millón, empleando la fecha de composición y de copia, respectivamente.

\begin{tabular}{|l|l|c|c|c|c|c|c|c|c|c|}
\hline & & XIII & XIV & XV & XVI & XVII & XVIII & XIX & XX & XXI \\
\cline { 1 - 9 } $\begin{array}{l}\text { venirle en } \\
\text { gana(s) }\end{array}$ & com & & & & 1 & 1 & & 5 & 76 & 1261 \\
\cline { 1 - 9 } & & & & 1 & & & 5 & \\
\hline
\end{tabular}

23 La transmisión manuscrita de textos suele introducir cambios que afectan su estudio lingüístico (p. ej. Fernández-Ordóñez 2002), por lo que un análisis diacrónico debería emplear textos cuya fecha de composición sea relativamente próxima a la de copia (Rodríguez Molina y Octavio de Toledo 2017). No obstante, con las estructuras que nos ocupan, las escasas ocurrencias de ciertas combinaciones no hace recomendable excluir testimonios relativamente tardíos. Por consiguiente, y para minimizar cualquier distorsión debida a la diferencia entre la fecha de composición y la de copia, aquí analizamos la frecuencia de uso con ambas fechas, buscando patrones clave que parecen independientes de la fecha empleada. Con todo, conviene subrayar que el uso de una u otra fecha no afectaría las conclusiones básicas que discutimos más adelante; la única diferencia notable es que atendiendo a la fecha de composición, la frecuencia relativa de las estructuras estudiadas caería ya a partir del XIII, mientras que según la fecha de copia, habría un aumento entre el XIII y el XV (véanse la Tabla 1 y las Figuras 1 y 2). 


\begin{tabular}{|c|c|c|c|c|c|c|c|c|c|c|}
\hline \multirow{2}{*}{$\begin{array}{l}\text { venirle a lal } \\
\text { en mente, } \\
\text { venirle al/en } \\
\text { pensamiento } \\
\text { y caerle } \\
\text { en (el) } \\
\text { pensamiento }\end{array}$} & com & & & 1 & 25 & \multirow[b]{2}{*}{11} & \multirow[b]{2}{*}{6} & & \multirow[b]{2}{*}{5} & \multirow[b]{2}{*}{9} \\
\hline & cop & & & & 26 & & & & & \\
\hline \multirow{2}{*}{ otras } & com & 32 & 19 & 40 & 17 & \multirow{2}{*}{21} & & \multirow{2}{*}{11} & \multirow{2}{*}{9} & \multirow{2}{*}{44} \\
\hline & cop & 8 & 15 & 56 & 28 & & 1 & & & \\
\hline
\end{tabular}

Tabla 1. Ocurrencias absolutas de las estructuras tipo venirle en

$N_{\text {intenc/deseo, }}$, por siglo de composición (com) y de copia (cop).

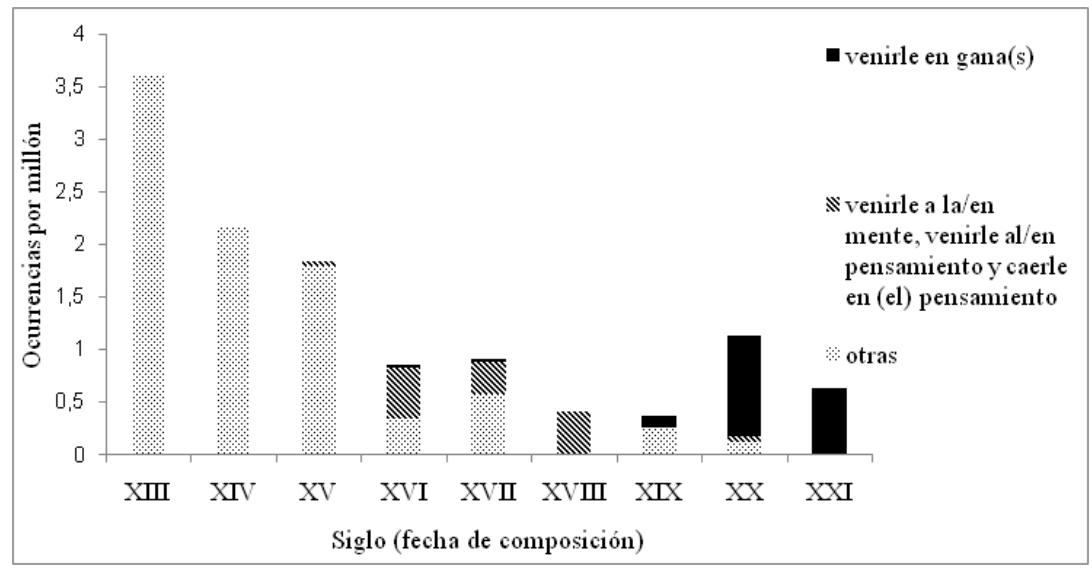

Gráfico 1. Ocurrencias por millón por siglo (fecha de composición)

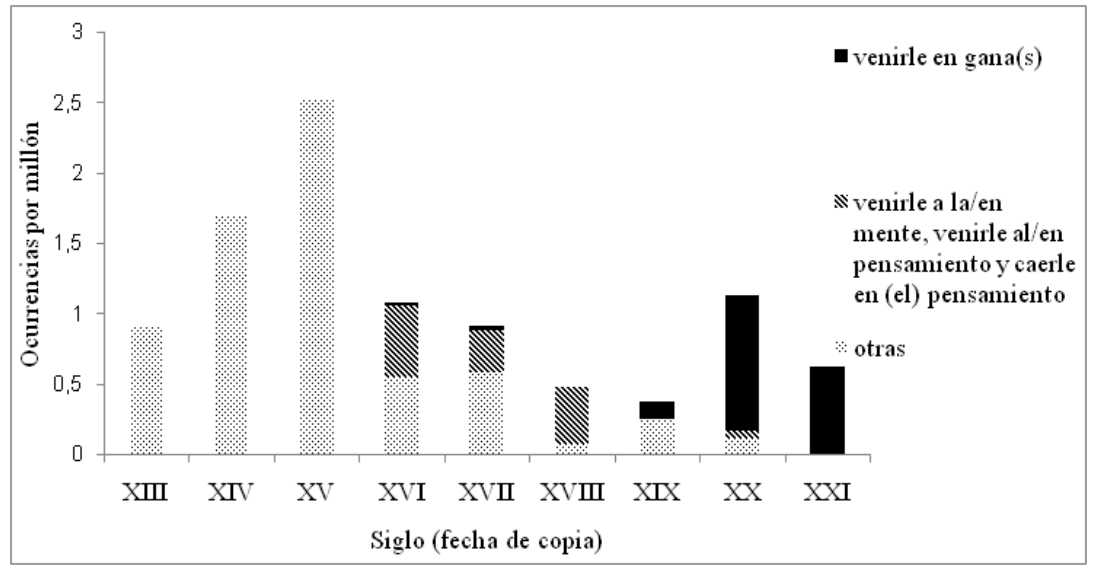

Gráfico 2. Ocurrencias por millón por siglo (fecha de copia) 
Como podemos ver, venirle en gana(s) se documenta a partir del XVI y es muy poco frecuente hasta el XIX, cuando aumenta sustancialmente el número de casos. Tras otro aumento aún más espectacular en el siglo XX, esta expresión monopoliza la inmensa mayoría de ocurrencias en el XXI, y es la única que se documenta con cierta frecuencia en todos los países representados en el subcorpus de dicho siglo. En contraste, venirle a la/en mente, venirle al/en pensamiento y caerle en (el) pensamiento se atestiguan a partir del XV o el XVI, y desde este último siglo las dos primeras acaparan entre un tercio (en el XVII) y tres terceras partes (en el XVIII) del total de casos. Sin embargo, después del XVIII su uso cae en picado, y en el XXI ya solo las encontramos marginalmente, con apenas 0,004 ocurrencias por millón. Por último, las otras combinaciones, documentadas desde el XIII, mantienen una frecuencia de uso bastante alta hasta el XV, pero sufren un descalabro en el XVI y el XVIII. Tras un ligero repunte en el XIX (que, como veremos más tarde, se debe casi exclusivamente a venirle en voluntad), estas otras combinaciones vuelven a caer en el XX y el XXI, cuando tienen una frecuencia irrisoria $(0,021$ ocurrencias por millón) y la gran mayoría -como también veremos- provienen de citas de siglos anteriores o ya no pertenecen estrictamente al subesquema intencional.

A la caída en picado de ocurrencias fuera de venirle al/en pensamiento y venirle a la/en mente en el Siglo de Oro se suma una drástica reducción en el número de combinaciones documentadas, que pasan de doce o trece en el XVI (dependiendo de si empleamos la fecha de composición o la de copia) a tan solo cinco en el XVII. El ocaso del subesquema intencional se confirma cuando examinamos con más detalle las ocurrencias atestiguadas a partir del XVIII. En efecto, en dicho siglo solo encontramos un caso de venirle en corazón en un manuscrito de Los Milagros de Nuestra Señora copiado en 1774-1778, y seis de venirle al pensamiento, p. ej. (20).

(20) $[. .$.$] no bien empezé a hacerlo, quando me vino al pensamiento$ determinar el modo con que procedería en la assistencia de un enfermo un médico [...]. (Cartas eruditas y curiosas, Benito Jerónimo Feijoo, 1750)

En el siglo XIX encontramos una ocurrencia de venirle en apetito, otra de venirle en gusto y cinco de venirle en gana(s), p. ej. (21). Sin embargo, estas expresiones se emplean con el sentido estativo de 'sentir $N_{\text {intenc/deseo,' }}$ (esto es, con la misma idea de 'apetecerle' o 'antojársele' que tiene ahora venirle en gana, cf. $D E A$ y $D R A E$, s.v. gana), y no con el significado ingresivo de 'empezar a sentir $N_{\text {'intenc/deseo' }}$ de hacer algo' (a saber, 'ocurrírsele') del subesquema intencional. Por otra parte, venirle en voluntad, documentado en nueve casos, todavía conserva su significado ingresivo original en 
algunas ocurrencias, p. ej. (22), pero en otras parece acercarse más a la interpretación estativa de 'apetecerle', p. ej. (23). Además, a partir de este siglo las combinaciones que sobreviven se emplean preferentemente sin infinitivo explícito, como en (21) y (23).

(21) La Sñra. Schoenebeck, cuyo marido la dejaba hacer cuanto la venía en gana, y que por no perturbarla ni siquiera residía en el mismo piso [...]. (Gotas de sangre, Luis Bonafoux, 1886) [CdE]

(22) [...], si por una inesperada casualidad, [...], le viniese en voluntad al señor Gallé, por el quidlibet audendi, de dar un punto más alto que otro en el aria de la Semíramis la noche que [...]. (Artículos, Mariano José de Larra, 1823)

(23) Estaba el Conciso muy tranquilo en su casa, pariendo siempre y cuando le venia en voluntad, y sin necesidad de hembra que le ayudase para tener hijos. (Cartas críticas del Filósofo Rancio, I, Fray Francisco Alvarado, 1811)

En el siglo XX encontramos ocho combinaciones. Como se ilustra en (24), tres tienen el sentido básico de 'apetecerle o antojársele' ya mencionado: venirle en deseo, venirle en gusto y venirle en gana(s), que acapara el $85 \%$ de casos. Por otra parte, venirle en voluntad aparece también como 'apetecerle o antojársele' en una ocurrencia (25), y en otros dos casos (ambos en la misma obra) que resultan ambiguos entre este sentido y su interpretación ingresiva original, p. ej. (26). Las cuatro combinaciones restantes conservan el sentido de 'empezar a sentir (u ocurrírsele) la intención de hacer algo', pero tres tienen solo una ocurrencia cada una. Además, una de estas (entrarle en voluntad) procede del romancero tradicional (27), otra (venirle al pensamiento) aparece en una cita de El castigo sin venganza de Lope de Vega, y la tercera (entrarle en ganas), en una cita del XIX. La única combinación que parece reflejar un uso ingresivo contemporáneo es venirle a la mente, de la que encontramos cuatro casos, p. ej. (28).

(24) [...] los hijos, o aquellos que administraban el templo, hacían como les venía en gusto y gana. (Trayendo a Dios a la casa, Néstor Martínez, 1971)

(25) Ya andan cerca de Aguascalientes, asaltando lo que les viene en voluntad, sin encontrar punto de reposo y [...]. (El tamaño del infierno, Arturo Azuela, 1973)

(26) [...] a un inglés extravagante y muy rico le vino en voluntad celebrar un concurso, [...]. (Sueños de Luciano Pulgar III, Marco Fidel Suárez, 1923) 
(27) No le matéis, mi señor, ni se os entre en voluntad. (Romances judeoespañoles de Tánger recogidos por Zarita Nahón, anónimo, 1929)

(28) Fatigados del teatro, al cabo nos vino a la mente fundar un Ateneo. (La novela de un novelista, Armando Palacio Valdés, 1921)

En el siglo XXI encontramos siete combinaciones diferentes. Venirle en gana(s), siempre como 'apetecerle o antojársele' (29), monopoliza el 96\% de casos. Con este mismo sentido aparecen entrarle en gana (30) (con ocho ocurrencias distribuidas en Colombia, España, Perú y Puerto Rico), caerle en gana (31) (documentada - por primera vez-en dos ejemplos de Colombia y México), y venirle en gusto (32), con un total de diez ocurrencias atestiguadas en Argentina, Costa Rica, España y Venezuela. Esta última expresión también se documenta, por primera vez, como venirle de gusto (33), que suma una cuarta parte del total de casos fuera de venirle en gana(s) en el siglo XXI (once, para ser exactos). Como señala Alba-Salas (2020), el hecho de que todos salvo dos casos de venirle de gusto parezcan proceder de Catalunya o de catalanoparlantes sugiere que esta realización preposicional es dialectal y obedece a la influencia de la expresión catalana venir(li) de gust 'tener ganas (de algo)' (CTILC y DIEC2, s.v. gust).

(29) Por eso este hombre hace lo que le viene en gana. (lainsignia.org, Jesús Blancornelas, 4/1/2005, México)

(30) Aún así no lo crítico, cada uno se gasta su dinero como bien le entra en gana, yo solo quiero invitar a la gente a [...]. (maquiyonkis.com, anónimo, España)

(31) Ahora sí le va a quedar más difícil inventar guerras injustificables a Estados Unidos y bombardear a civiles como se les caiga en gana sin que el mundo se entere. (joannacastro.wordpress.com, anónimo Colombia)

(32) Haz ejercicio (caminar, nadar, bicicleta, gimnasio) lo que te venga en gusto pero variado. (mx.answers.yahoo.com, Jurassic [seudónimo], 2008, México)

(33) ¿Qué andaba haciendo?, ahora no me viene de gusto explicártelo [...]. (barcelona.indymedia.org, super-revolucionarix [seudónimo], 2013, España)

Las otras tres combinaciones documentadas en el siglo XXI conservan un sentido ingresivo. Sin embargo, como en el siglo XX, la única que parece corresponder a un uso coetáneo es venirle en mente (34), atestiguada (esta vez con en y sin artículo) en un total de nueve ocurrencias en Argentina, Colombia, Cuba, Ecuador, El Salvador, España, México, Paraguay y Perú. En contraste, venirle en voluntad solo se documenta en citas del Siglo 
de Oro, mientras que venirle en deseo aparece en una cita del XVI y una traducción con un lenguaje claramente arcaizante donde el infinitivo está nominalizado (35).

(34) La mayoría de las veces cuando hablamos de Google en la empresa, únicamente nos viene en mente utilizarla como página de inicio o como buscador. (tecnologiaslibres.com, David Cuní, 11/4/2013, Cuba)

(35) De lo que habrían difamado muchas cosas con las cuales hubiera a la inocente mujer contristado, y aun quizás héchole venir en deseo el volver a desear lo que ya había sentido [...]. (Decamerón (Boccacio), trad. anónimo, 2009, Colombia)

En resumen, los datos del corpus sugieren que el subesquema intencional se perdió esencialmente durante el Siglo de Oro, cuando observamos una contracción muy brusca en el número de ocurrencias y de combinaciones. Aunque tras el XVII todavía encontramos vestigios (sobre todo con venirle al pensamiento, venirle en voluntad y venirle a la/en mente), su frecuencia relativa es bajísima, y solo venirle en mente parece haberse conservado hasta el siglo XXI en algunos países con el sentido ingresivo de 'ocurrírsele'. La única expresión que se mantiene con una frecuencia notable en todas las áreas lingüísticas consideradas es venirle en gana(s), pero como 'apetecerle o antojársele', el mismo sentido estativo de otras tres combinaciones documentadas marginalmente: caerle en gana, entrarle en gana y venirle en gusto (o, en zonas catalanoparlantes, venirle de gusto).

Nuestra hipótesis es que la pérdida del subesquema intencional habría obedecido a dos cambios relacionados que discutimos a continuación: su lexicalización o construccionalización léxica, y su caída en desuso u obsolescencia.

\section{LA LEXICALIZACIÓN DEL SUBESQUEMA INTENCIONAL}

\subsection{LA LEXICALIZACIÓN COMO CONSTRUCCIONALIZACIÓN LÉXICA}

La lexicalización suele entenderse como un proceso en el que las unidades complejas o sintagmáticas dejan de ajustarse a las reglas gramaticales generales y se convierten en unidades léxicas (Bustos Plaza 2005: 128-131; cf. Brinton y Traugott 2005). Traugott y Trousdale (2013) han reconcebido esta idea tradicional en el marco de la Gramática de Construcciones, donde 
no existe una frontera rígida entre el léxico y la gramática ${ }^{24}$. Según Traugott y Trousdale, a diferencia de los cambios construccionales, que modifican solo un aspecto de una Construcción (como su forma, su significado o su distribución), la construccionalización conlleva la creación de una nueva Construcción con una forma y un significado nuevos (2013: 22-27). Salvo en casos de acuñación léxica instantánea, la construccionalización tiene lugar a través de reanálisis (o, en su terminología, neoanálisis) graduales tanto de la forma como del significado. El proceso empieza cuando un oyente interpreta un constructo (una ocurrencia específica de una Construcción en un contexto determinado) de una manera diferente que el hablante que lo produjo. El oyente crea un enlace tenue entre el constructo en cuestión y una parte nueva de la red construccional, y luego vuelve a usar el constructo (como hablante) con el nuevo sentido o con una distribución nueva. La innovación se convencionaliza cuando otros hablantes y oyentes siguen procesos similares y una comunidad alcanza un acuerdo tácito sobre la relación que existe entre la forma original y el significado reanalizado. Este reanálisis semántico (un cambio construccional) crea una falta de correspondencia entre la morfosintaxis de la Construcción original y su nuevo significado, lo cual lleva a algunos hablantes a reanalizar también la forma de dicha Construcción (otro cambio construccional). Cuando una comunidad comparte el mismo reanálisis de la forma y el significado, aparece una nueva Construcción, y hablamos ya de construccionalización (2013: 91-93). Dependiendo de su posición en un continuum de esquematicidad, la nueva Construcción puede ser una micro-Construcción (un miembro-tipo de contenido potencialmente

24 La Gramática de Construcciones engloba varios enfoques donde las Construcciones son la unidad básica de análisis (cf. nota 16). Según Goldberg (2013), estos enfoques comparten cuatro postulados esenciales: (a) la idea de que tanto las unidades sintagmáticas como los ítems léxicos son Construcciones, de manera que el léxico y la sintaxis forman un continuo; (b) la asociación directa de la forma y el contenido semántico de una expresión, sin derivaciones ni transformaciones; (c) el análisis de las diferencias interlingüísticas como resultado de procesos cognitivos de dominio general; y (d) la conceptualización de nuestro conocimiento lingüístico como una red mental de Construcciones o Constructicón organizado jerárquicamente y compuesto de nodos que se relacionan no solo a través de enlaces de herencia que permiten que una Construcción herede propiedades de Construcciones más generales, sino también mediante enlaces relacionales tales como la polisemia, la extensión metafórica, la instanciación, y la relación de subparte (cf. Goldberg 1995: 75-84 y 97). Además, la mayoría de enfoques asumen que (a) los hablantes reconfiguran su Constructicón continuamente a través de su experiencia lingüística, (b) la semántica, la pragmática y la estructura informacional contribuyen a la función lingüística, y (c) la categorización implica generalizaciones basadas en ejemplares prototípicos y extensiones convencionalizadas, a menudo metonímicas o metafóricas (Goldberg 2013: 16; véanse, entre otros, Barðdal et al. 2015, Goldberg 2006, Hoffmann y Trousdale 2013 y Traugott y Trousdale 2013). 
referencial que se sitúa en los niveles más bajos de la red construccional), un subesquema (de semántica más general y constituido por varias microConstrucciones que siguen el mismo patrón formal y semántico), o un esquema, a saber, una Construcción aún más abstracta que aparece en los niveles más altos del Constructicón y que formamos generalizando a partir de subesquemas que percibimos inconscientemente como relacionados (2013: 13-14).

Traugott y Trousdale distinguen la construccionalización gramatical (cuyo resultado es una Construcción con una semántica procedimental y abstracta que sirve para marcar relaciones lingüísticas, perspectivas $\mathrm{y} / \mathrm{u}$ orientación deíctica) de la construccionalización léxica, que crea una Construcción con una semántica de contenido potencialmente referencial (2013: 192-194). Lo que suele denominarse lexicalización sería un subtipo de construccionalización léxica que crea micro-Construcciones atómicas o no-composicionales a partir de micro-Construcciones complejas o composicionales (2013: 182-186). Siguiendo a Lehman (2002: 157), Traugott y Trousdale sostienen que el cambio afecta a una unidad sintagmática del tipo $[X Y]_{Z}$, que deja de ser compleja y empieza a accederse como un todo al eliminarse la relación de dependencia que existía entre $X$ e $Y$ (2013: 158). El resultado no solo es la pérdida de composicionalidad semántica y analizabilidad sintáctica de las micro-Construcciones afectadas, sino también la pérdida de productividad del (sub)esquema asociado, que se desvincula de las unidades lexicalizadas y, por tanto, reduce su frecuencia de tipos (en contraste con su frecuencia de ocurrencias o tokens; 2013: 181 y 191).

\subsection{LA CONSTRUCCIONALIZACIÓN LÉXICA DEL SUBESQUEMA INTENCIONAL}

Como en los casos típicos de construccionalización, la lexicalización del subesquema intencional habría conllevado un reanálisis gradual de su forma y significado. El reanálisis semántico del subesquema de 'intención' habría supuesto la pérdida tanto de su composicionalidad semántica como de su sentido ingresivo original. El detonante habría sido otro cambio en la red construccional: la desaparición de la CVA haber/tener en/(a) $N_{\text {intenc/deseo., }}$ entendida como otro subesquema construccional (con el significado de "sentir $N_{\text {intencldeseo' }}$ de hacer algo'; cf. § 1). La Tabla 2 presenta las ocurrencias por millón por siglo de los 1847 casos no repetidos de esta CVA que aparecen en el CORDE y el $C d E$ con los diez sustantivos documentados en el subesquema intencional (ánimo, apetito, corazón, deseo, gana(s), gusto, mente, pensamiento, propósito y voluntad), cf. (10), (11) y (15). Puesto que la inmensa mayoría de ocurrencias (1419, para ser exactos) incluyen mente, 
este sustantivo se muestra por separado ${ }^{25}$. También se desglosan aparte los casos con gana(s), dado el estatus especial de venirle en gana(s).

Como podemos ver, haber/tener en gana(s) se documenta solo entre el XV y el XVII, y con una frecuencia muy baja. Por otra parte, tener en (la) mente (solo con tener y en su sentido relevante de 'sentir la intención de hacer algo') se atestigua desde el XVIII, y es la única combinación que aumenta su frecuencia de uso en el XX y, sobre todo, en el XXI, cuando sin embargo se comporta como una expresión de sintaxis fija ${ }^{26}$. En contraste, los otros nombres -atestiguados con haber y/o tener con una frecuencia bastante alta durante el Medievo- caen en picado en el XVI y el XVII, y tienen un uso marginal a partir del XVIII ${ }^{27}$. La conclusión, pues, es que haber/tener en/ (a) $N_{\text {intenc/deseo }}$ dejó de ser productiva en el Siglo de $\mathrm{Oro}^{28}$, dejándonos solo tener en (la) mente -al parecer, una innovación postclásica- como reliquia fosilizada de uso general ${ }^{29}$.

\begin{tabular}{|c|c|c|c|c|c|c|c|c|c|c|}
\hline & & XIII & XIV & XV & XVI & XVII & XVIII & XIX & $\mathrm{XX}$ & XXI \\
\hline \multirow{2}{*}{ gana(s) } & compos. & & & \multirow{2}{*}{0,09} & \multirow{2}{*}{0,12} & \multirow{2}{*}{0,05} & & & & \\
\hline & copia & & & & & & & & & \\
\hline \multirow{2}{*}{ mente } & compos. & & & & & & \multirow{2}{*}{0,14} & & \multirow{2}{*}{0,17} & \multirow{2}{*}{0,668} \\
\hline & copia & & & & & & & & & \\
\hline \multirow{2}{*}{ otros } & compos. & 3,94 & 6,22 & 7,55 & 2,55 & 0,44 & \multirow{2}{*}{0,14} & & \multirow{2}{*}{0,08} & \multirow{2}{*}{0,003} \\
\hline & copia & 1,24 & 5,09 & 7,24 & 3,32 & 0,49 & & & & \\
\hline
\end{tabular}

Tabla 2. Ocurrencias por millón de haber/tener en/(a) $N$ con los sustantivos documentados en el subesquema intencional, por siglo de composición y de copia

25 Del resto de casos, 28 son con pensamiento, 10, con gana(s), y 390, con los otros sustantivos.

26 En el siglo XXI tener en mente aparece 'tal cual' en el 98,3\% de casos, p. ej. "Es curioso pero tenía en mente hacer el mismo comentario que Joserra" (blogs.salleurl.edu, Miguel Sierra, 28/4/2010, España), y con artículo, en el 1,7\% restante. Según los hablantes nativos consultados, en tener en (la) mente (siempre en su sentido relevante) mente no puede modificarse, cf. *tener en mucha/pocaltanta mente.

27 Además, las escasísimas ocurrencias de después del XVII (con pensamiento, propósito y voluntad) suelen aparecer en citas de siglos anteriores.

28 La pérdida de esta CVA se enmarca dentro de la caída en desuso de las colocaciones tipo en + nombre de estado en el Siglo de Oro (Alba-Salas 2016b; cf. Dubský 1963), un cambio que también contribuyó a la lexicalización y caída en desuso de otra Construcción distinta estudiada en Alba-Salas (2020).

29 De las combinaciones analizadas, tener en (la) mente es la única que se recoge (s.v. mente) en los diccionarios modernos consultados. Así, el $D R A E$ y el $D U E$, pero no el $D E A$, la incluyen (con artículo en el $D R A E$ y sin él en el $D U E$ ) con el sentido de 'tener (algo) pensado o prevenido/previsto', mientras que en el REDES y el DCPEC aparece sin artículo y (según el $D C P E C$ ) como 'tener intención de hacer algo'. 
La desaparición de haber/tener en/(a) $N_{\text {intenc/deseo }}$, habría conllevado la pérdida de composicionalidad semántica de las estructuras tipo venirle en/(a) $N_{\text {intenc/deseo, }}$ que ya no habrían podido entenderse como versiones ingresivas de las CVA correspondientes. El cambio se habría extendido micro-Construcción por micro-Construcción a medida que se extinguía cada CVA, abriendo las puertas para que las combinaciones afectadas y todo el patrón construccional derivado por abstracción se reinterpretaran de forma estativa, esto es, como 'sentir o experimentar $N_{\text {intenc/deseo }}$, de hacer algo'. Este reanálisis semántico habría explotado una propiedad clave asociada con la doble predicación del subesquema intencional: el hecho de que 'empezar a sentir' implica necesariamente 'sentir'. En virtud de esta implicación, al activarse la predicación ingresiva de 'empezar' (la predicación focalizada cuando todavía existía la CVA correspondiente con haber o tener), se activaba automáticamente la predicación estativa de 'sentir' en el trasfondo. A medida que desaparecía tener/haber en/(a) $N_{\text {intenc/deseo, }}$ y se debilitaba la idea de 'empezar', esta predicación estativa se habría impuesto de forma natural. Así, por ejemplo, venirle en/(a) voluntad (de hacer algo), que inicialmente se habría entendido como 'empezar a sentir voluntad (de hacer algo)' gracias a su relación semántica y estructural con haber/tener en/(a) voluntad (de hacer algo), se habría reinterpretado como 'sentir voluntad (de hacer algo)', esto es, 'apetecerle o antojársele (hacer algo)'.

El reanálisis estativo del subesquema de 'intención' resulta particularmente evidente en venirle en gana(s). Como otras combinaciones, esta expresión estaba asociada inicialmente con una CVA: haber/tener en gana(s) de + infinitivo (36). Sin embargo, sus primeras ocurrencias (solo dos entre el segundo cuarto del XVI y principios del XVII) resultan ya ambiguas entre 'empezar a sentir ganas de hacer algo', a saber, 'ocurrírsele hacer algo', y 'sentir ganas de hacer algo', es decir, 'apetecerle o antojársele hacer algo' (37). Esta ambigüedad parece obedecer no solo a la escasa productividad histórica de la CVA haber/tener en gana(s), atestiguada por última vez en el XVII (cf. Tabla 2), sino también a la incorporación relativamente tardía de venirle en gana(s) al subesquema intencional (cf. Tabla 1), al que se habría integrado como miembro periférico, y por lo tanto menos asociado con sus rasgos prototípicos.

(36) [...], y como el rey y reyna touiesen mucho en gana de le soltar y vieron tiempo más aparejado, [...]. (Crónica incompleta de los Reyes Católicos, anónimo [¿Juan de Flores?], compuesto 1476 ad quem o 1477 a quo - 1500, copiado 1491 ca. -1505 ca. o 1501 ca. -1510 ca. [RAH, 9/466]) 
(37) Tal libertad exige [...] que no prestemos oídos al embuste, que no digamos lo que nos venga en gana, sino sólo aquello en que resplandezca la verdad y, [...]. (Epistolario. Selección, Juan Ginés de Sepúlveda, 1532) [CdE]

En todo caso, hoy en día venirle en gana(s) -al igual que entrarle/caerle en gana(s) y venirle en gusto (cf. § 2)- tiene una semántica semitransparente, pero -al haberse perdido haber/tener en gana(s) - ya no es ingresiva ni del todo composicional ${ }^{30}$. Esto lo confirma el hecho de que el $D R A E$ caracterice venirle en gana(s) (s.v. gana) como una locución, esto es, como un "grupo de palabras que funcionan como una sola pieza léxica con un sentido unitario y cierto grado de fijación formal" (s.v. locución).

La pérdida del sentido ingresivo del subesquema intencional se habría completado esencialmente para finales del XVII, cuando (según los datos de la Tabla 2) la CVA haber/tener en/(a) $N_{\text {intenc/deseo, }}$ dejó de ser productiva. En efecto, como vimos en la sección 2, la mayoría de combinaciones documentadas a partir del XVIII tiene una interpretación estativa: venirle en apetito/deseo/gana(s), venirle en/(de) gusto y entrarle/caerle en gana(s). $\mathrm{Al}$ margen de citas de siglos anteriores o de ejemplos que reflejaban usos aparentemente anticuados, las únicas excepciones pertenecían a dos grupos. El primero incluía venirle en voluntad, la combinación más frecuente en la mayoría de siglos desde el XIII al XX, cuando deja de documentarse. Esta expresión habría mantenido la idea de 'empezar' en algunas ocurrencias gracias a su mayor arraigo histórico (y, por tanto, también mayor asentamiento cognitivo) con este significado, algo que no debería sorprendernos dado que -como señalan Bybee (2015: 224) y Traugott y Trousdale (2013: 68)- las Construcciones de alta frecuencia tienden a dejar vestigios que se aprenden como un todo y que ya no se perciben como parte de un patrón general. El segundo grupo incluía las dos expresiones que han conservado hasta hoy el sentido de 'ocurrírsele' en su uso con complementos nominales: venirle al pensamiento (38) y, sobre todo, venirle en mente (39).

(38) ¿Habrán contado o contarán con [...] Ortega o Plácido Domingo, por citar sólo algunos nombres que me vienen al pensamiento? (ABC noticias, Luis Bru, 1993, España) [CdE]

30 Decimos del todo porque, como es bien sabido, ni la composicionalidad semántica ni la fijación sintáctica son propiedades binarias, sino escalares y muy variables (p. ej. Nunberg, Sag y Wasow 1994, Wulff 2013, Traugott y Trousdale 2013: 19-27). 
(39) Solemos invertir tanta energía en cacarear la primera idea que nos viene en mente que [...]. (cafefuerte.com, Ramón Alejandro, 10/2/2013, Cuba)

Venirle al pensamiento y venirle en mente habrían conservado su sentido ingresivo con infinitivos solo como parte de su uso más general de 'ocurrírsele (algo)' con complementos nominales, incluyendo -al desaparecer de como marca del infinitivo sujeto (cf. nota 9)-infinitivos nominalizados, cf. (35) ${ }^{31}$. Este uso más general de venirle al pensamiento y venirle en mente ya no está asociado inherentemente con la 'intención de hacer algo' que tenía el subesquema intencional. En todo caso, la pérdida de dicho subesquema como patrón semántico coherente se confirma con dos hechos: que venirle al pensamiento (hacer algo) se documente por última vez, y fuera de citas de siglos anteriores, en el siglo XVIII ${ }^{32}$; y que venirle en mente (al parecer, solo con en) parezca ser la única combinación que se haya conservado en el XXI con la idea de 'ocurrírsele hacer algo', pero con una frecuencia irrisoria, solo en ciertas variedades y (al haberse perdido el uso de mente como 'intención o voluntad', cf. nota 20) ya sin la posibilidad de poder parafrasearse composicionalmente como 'empezar a sentir (u ocurrírsele) la mente de hacer algo' ${ }^{33}$.

La pérdida de composicionalidad semántica del subesquema de 'intención' habría llevado también al reanálisis de su forma, un cambio que habría supuesto la fijación sintáctica del sintagma preposicional en el que aparecía el nombre de ‘intención' o 'deseo'. Como señalábamos en la sección 1, en el subesquema de 'intención' original, dicho nombre solía aparecer desnudo, pero algunos nombres podían llevar artículo (cf. (13) y la nota 6). A partir del segundo cuarto del XVII, ya no encontramos ocurrencias

31 Dentro del subesquema intencional, la pérdida de esta marca preposicional parece haberse completado esencialmente entre el XVI y el XVII; a partir del XVIII las ocurrencias son escasísimas.

32 Los dos últimos casos (ambos en la misma obra) incluyen un infinitivo nominalizado, p. ej. "Ni era necesario haber visto las pirámides de Egipto, para que viniera al pensamiento a los mexicanos el hacer semejantes edificios [...]" (Historia Antigua de México, Francisco Clavijero, 1780). Ello confirma el realineamiento de venirle al pensamiento + infinitivo con el uso más general de 'ocurrírsele (algo)'.

33 De hecho, al margen de venirle en gana(s), el único vestigio del subesquema intencional que hemos podido encontrar en los diccionarios modernos consultados es venirle a la mente (pero no venirle en mente), que se recoge en el REDES y el DCPEC. No debería extrañarnos que el único ejemplo de esta expresión recogido en dichos diccionarios (cuando me mencionaste el asunto, me vino a la mente un nombre, en el DCPEC) ilustre su uso más general con sustantivos, y no como 'la intención de hacer algo'. 
con artículo entre los sustantivos que permitían tal alternancia. La única excepción son pensamiento y mente, atestiguados por última vez con artículo en el XVIII y el XX, respectivamente. En ambos casos, el artículo aparece siempre con la preposición a (venirle al pensamiento/a la mente). Al parecer, pues, la conclusión es que a partir del XVII el sintagma preposicional se fijó sintácticamente, bien como en $N$ (en su realización prototípica) o (en el caso de mente y pensamiento) como $a+$ artículo $+N$.

La fijación del sintagma preposicional en el que aparecía el nombre de 'intención' o 'deseo' se confirma indirectamente cuando consideramos la posibilidad de modificar dicho nombre con otros elementos además de un artículo. Con una sola excepción a la que volveremos más adelante, ni el $C O R D E$ ni el $C d E$ incluyen ocurrencias del subesquema intencional donde $N_{\text {intenc/deseo }}$, aparezca modificado de esta manera. Sin embargo, entre el XIII y el XVII sí encontramos una docena de casos (un 3\% del total entre ambos siglos) de la CVA haber/tener en/(a) $N_{\text {intenc/deseo }}$, en los que el nombre de 'intención' o 'deseo' va precedido de los cuantificadores gran(d) o mucho, p. ej. (40) y (41), por lo que parece razonable asumir que esta posibilidad también habría existido inicialmente en las estructuras con venir, entrar o caer, pero que se habría actualizado solo ocasionalmente debido a la naturaleza del sustantivo de 'intención' o 'deseo' como un nombre discontinuo y, por tanto, menos propenso a la modificación.

(40) E tenía por çierto en grand deseo, muchos días avía, de retraherse a su maestrazgo, e fazer guerra a los moros, e serbir [...]. (Crónica de Don Álvaro de Luna, anónimo, compuesto 1445-1500, copiado 14011600 [BNE, 10141])

(41) $[\ldots]$ antes que él nasçiese, e [que] él avía a gran voluntad de lo delibrar por armas, [...]. (El Victorial, Gutierre Díaz de Games, compuesto 1431 a quo -1435 ad quem, copiado 1451-1510 ca. [BNE, 17648])

Nuestra hipótesis es que el nombre de 'intención' o 'deseo' habría perdido su libertad sintáctica durante el siglo XVII, dejando en $N$ o (en el caso de mente y pensamiento) $a+$ artículo $+N$ como una secuencia fosilizada. La fijación de en $N$ queda particularmente clara en el venirle en gana(s) moderno. Aunque el $C d E$ incluye una ocurrencia en el siglo XXI donde gana aparece modificado (42), dicho ejemplo contiene un intensificador estereotipado -real-que aparece en otras expresiones idiomáticas con gana (p. ej. no darle la real/realísima gana, cf. DEA, s.v. gana) y que no puede ir pospuesto (*le viene en gana real) ni modificarse con un adverbio (??(se) les viene en (la) muy real gana). 
(42) $[. .$.$] que puede ser repartido entre socios [...] y hasta amantes, como a$ ellos se les viene en real gana. (elcoloo.com, Gerardo Meza, 13/3/2013, Paraguay)

El estatus de en gana(s) como una secuencia fosilizada es consistente con la observación de Alba-Salas (2017) de que en el venirle en gana(s) moderno, gana(s) -típicamente en singular; cf. nota 18- no puede modificarse con adjetivos fuera de real (*me vino en una(s) gana(s) enorme(s)), relativizarse (*la(s) gana(s) en que me vino), ni moverse (*iEn cuánta(s)/qué gana(s) me vino!). En contraste, en la estructura dativa simple venirle gana(s) del siglo XXI, que todavía tiene el sentido ingresivo y composicional de 'empezar a tener (esto es, sentir) ganas (de hacer algo)' (cf. § 1), gana(s) -casi siempre en plural, según los datos del $C d E$ - mantiene su autonomía sintáctica, por lo que puede relativizarse (las ganas que me vienen), moverse (;Cuántas/ qué ganas me vienen de...!) y modificarse con adjetivos y cuantificadores (me vienen muchas ganas/unas ganas enormes). Según los hablantes nativos consultados, la misma falta de libertad sintáctica de venirle en gana(s) también afecta a otros vestigios marginales del subesquema intencional documentados en el siglo XXI, incluyendo no solo caerle/entrarle en gana(s) y venirle en/(de) gusto (??me caelentra en mucha/tanta gana, *le viene en/de mucho/tanto gusto), sino también venirle en mente (*nos viene en mucha/tanta mente).

En contraste con su forma inicial, en la estructura reanalizada de los escasos vestigios del subesquema de 'intención' documentados tras el XVII, $N_{\text {intencldeseo }}$, ya no encabezaría un sintagma nominal dentro del sintagma preposicional en el que aparece (a saber, $\left[_{\text {SPrep }}\right.$ en/a $\left.\left[_{S N} N_{\text {intenc/deseo }}\right]\right]$ ), sino que sería parte de la secuencia fija en $N$ (esto es, $\left[_{\text {SPrep }}\right.$ en $\left.\left.N_{\text {intenc/deseo }}\right]\right)$, o -en el caso de venirle al pensamiento y venirle a la mente- $\Gamma_{\text {SPrep }}$ al pensamiento/a la mente]. Este cambio se habría producido por recodificación o chunking, un mecanismo cognitivo que toma una secuencia de elementos que se linearizan exclusiva o preferentemente en el mismo orden y la transforma en una unidad que se recuerda y procesa como un todo (Bybee 2015: 238-239, Fried, 2013). Al igual que el reanálisis semántico, este cambio habría ocurrido gradualmente, a medida que se reanalizaba y convencionalizaba la forma de cada combinación. Al perder su composicionalidad semántica y libertad sintáctica, lo que originalmente eran unidades complejas terminaron siendo micro-Construcciones atómicas con una forma y un significado nuevos. 


\section{LA OBSOLESCENCIA DEL SUBESQUEMA INTENCIONAL}

Según Traugott y Trousdale (2013: 65-71), un (sub)esquema pierde productividad no solo al reducirse su frecuencia de tipos, sino también cuando disminuye su frecuencia de ocurrencias o tokens, un cambio construccional que lleva a la caída en desuso u obsolescencia de dicho (sub)esquema. Esto es así porque la frecuencia de ocurrencias determina el asentamiento cognitivo de las Construcciones situadas en los niveles más bajos del Constructicón (2013:17-19). Mientras que la exposición repetida a constructos similares lleva a los hablantes a crear un nuevo (sub)esquema generalizando patrones comunes, el uso infrecuente de una Construcción -manifiesto en una escasez de ocurrencias- debilita su asentamiento cognitivo en la red construccional, de manera que dejamos de interpretar los constructos como parte de un (sub)esquema productivo (2013: 68-71). Como resultado, el (sub)esquema legitima cada vez menos constructos, y patrones que antes habían sido productivos y composicionales se vuelven idiosincrásicos e improductivos, contribuyendo a su lexicalización ${ }^{34}$. Esto mismo habría ocurrido con el subesquema intencional en el XVI y el XVII. Al igual que la lexicalización, este cambio habría tenido lugar microConstrucción por micro-Construcción (cf. Traugott y Trousdale 2013: 66), dejándonos tan solo venirle en gana(s) y otras expresiones de uso marginal como vestigios fosilizados que ya no percibimos como parte de un patrón general (cf. Traugott y Trousdale 2013: 68).

Al margen de la caída en desuso de algunos de los nombres incluidos en el subesquema intencional (sobre todo corazón y mente, entendidos en su sentido antiguo de 'intención'), un factor clave en la obsolescencia de dicho subesquema habría sido la competencia con otro subesquema: las estructuras 'simples' (no preposicionales) tipo venirle $N$ que ya hemos mencionado, p. ej. venirle gana(s)/deseo/voluntad. Este otro subesquema, al que por comodidad nos referiremos como $V$-le $N$ (esto es, verbo + dativo + nombre predicativo), constituía una versión ingresiva de la CVA 'simple' haber/

34 Un ejemplo del inglés serían los sustantivos warmth 'calor', health 'salud' y truth 'verdad', que originalmente estaban asociados con un subesquema productivo que creaba sustantivos abstractos a partir de adjetivos y el sufijo th. Con el tiempo, este subesquema cedió terreno frente a otros subesquemas con la misma función semántica (adjetivo + ness y adjetivo + ity). $\mathrm{Al}$ final, adjetivo + th quedó obsoleto, y lo que se asentó cognitivamente en las generaciones futuras no fue el patrón general, sino solo las formas warmth, health y truth, reanalizadas como micro-Construcciones monomorfémicas (2013: 68-69). 
tener $N$ (43) y compartía con el subesquema de 'intención' el significado de 'empezar a sentir $N$ ', hasta el punto de que -a juzgar por la existencia de dobletes como los que se recogen en el Quijote, esto es venirle en voluntad $y$ deseo, venirle gana y voluntad y venirle deseo, cf. (1) y (12)- parecían intercambiables con algunos nombres.

(43) Pero si ouo uoluntad quando alli entro de no beuir mas al sieglo; no puede mas tornar a [...]. (Primera partida, Alfonso X, compuesto 1256-1265, copiado 1290 [British Library, Add. 20787])

$\mathrm{Al}$ igual que el subesquema intencional, $V$-le $N$ se documenta desde el XIII con venir y entrar, pero no con caer, que no parece haber sido productivo en estos dos subesquemas (Alba-Salas 2016a, 2016b, 2017). V-le $N$ se habría impuesto no solo porque el subesquema intencional perdió productividad al lexicalizarse, sino también porque la Construcción 'simple' poseía tres ventajas clave. La primera es la mayor coherencia semántica y estructural de las micro-Construcciones asociadas, ya que, a diferencia del subesquema de 'intención', $V$-le $N$ no mostraba alternancias preposicionales (en/a) y mantuvo en todo momento su sentido ingresivo original. La segunda es que, gracias a su asociación con la CVA haber/tener $N$ (esto es, 'sentir $N$ '), que se ha empleado históricamente con una variedad mucho mayor de nombres predicativos y que todavía se mantiene productiva, $V$ - $l e N$ pudo conservar una semántica transparente y composicional: 'empezar a tener o sentir $N^{35}$. La tercera ventaja es una mayor frecuencia tanto de tipos como de ocurrencias. Es cierto que el subesquema intencional se documenta con tres sustantivos con los que $V$-le $N$ no parece haber sido productivo (corazón, mente y propósito), y también que, atendiendo a los datos del CORDE y el CdE, tanto venirle en/a voluntad como la menos común entrarle en voluntad parecen haber sido más frecuentes que venirle/entrarle voluntad en el Medievo y el Siglo de Oro (lo cual habría contribuido a la mayor longevidad histórica de venirle en voluntad, cf. § 2). Sin embargo, $V$-le $N$ se atestigua con gana(s) y deseo con muchísima mayor frecuencia que el subesquema intencional hasta el XVIII. En efecto, venirle gana(s) (de hacer algo) -documentada desde el XV, un siglo antes que venirle en gana(s) - suma 28 casos entre el XVI y el XVIII, frente a tan solo dos de venirle en gana(s) (cf. Tabla 1), mientras que venirle deseo(s) (de hacer algo) tiene 23 ocurrencias en

$35 V$-le $N$ y tener/haber $N$ se basan en la metáfora conceptual de 'sentir o experimentar' un estado o una situación como 'tener' dicho estado o situación (véanse Alba-Salas 2016b, 2017 para más detalles). 
el mismo periodo, frente a solo cuatro de venirle en deseo. Por otra parte, entrarle deseo(s) (de hacer algo) - a diferencia de entrarle en deseo, que no aparece en nuestros dos corpus- se atestigua ininterrumpidamente desde el XVI hasta hoy ${ }^{36}$. Además, históricamente, $V$-le $N$ supera con creces al subesquema intencional tanto en combinaciones como en ocurrencias, ya que se documenta con muchísimos más sustantivos además de los de 'intención'y 'deseo'. De hecho, sumando todos los siglos analizados, venirle en/(a) $N$ solo se documenta con diez nombres, y entrarle en $N$, con cuatro, cf. (13). En contraste, nuestro estudio anterior sobre el uso de venir con 81 sustantivos predicativos documenta venirle $N$ con 47 nombres desde el XIII al XV, 55 entre el XVI y el XVII, y 35 entre el XVIII y el XX (véase Alba-Salas 2017), y nuestro análisis de entrar con 56 sustantivos de estado atestigua entrarle $N$ con ocho nombres desde el XIII al XV, diez entre el XVI y el XVII, y 40 entre el XVIII y el XX (sobre todo a partir del XIX, cuando entrarle $N$ se impone a las otras realizaciones con las que había competido en siglos anteriores: entrar alguien en $N$ y entrar $N$ en alguien; véase Alba-Salas 2016b) ${ }^{37}$.

Estas tres ventajas habrían sido particularmente valiosas en el contexto sociolingüístico que caracterizó al español del XVI y el XVII. Como es bien sabido, el Siglo de Oro fue un periodo de consolidación de una profunda reestructuración de la fonología y la morfosintaxis, y algunos de los cambios -como la desaparición de la /h-/ inicial y de las sibilantes sonoras- parecen constituir simplificaciones sistémicas sin paragón entre las lenguas románicas (p. ej. Lapesa 1981:367-417, Penny 2000: 48-49, Pensado 1993, Tuten 2003: 4). Penny (2000: 42-46) argumenta que tales simplificaciones se habrían debido a la mezcla dialectal que acompañó al movimiento demográfico masivo desencadenado por la reubicación de la corte a Madrid en 1561. Esta mezcla habría llevado a la aparición de una koiné, una nueva variedad que difería en cierto grado de todas las que entraron en la mezcla (Lapesa 1996: 58, Penny 2000: 45-56 y 199, Tuten 2003: 4). La koiné de Madrid habría cobrado forma gracias a dos procesos clave: la simplificación, que favorece la forma más simple entre las competidoras y conlleva un aumento

36 Lo mismo podría decirse de entrarle gana $(s)$, que se documenta siempre en un número mucho mayor de casos que entrarle en gana(s), pero que no consideramos relevante para el argumento que desarrollamos aquí porque se atestigua solo a partir del XIX, un siglo antes que entrarle en gana(s).

37 Algo similar ocurre con caer, pese a su estatus marginal tanto en $V$-le $N$ como en el subesquema de 'intención': mientras que caerle en $N$ solo se documenta con tres nombres, cf. (14), caerle $N$ aparece con ocho de los 109 sustantivos de situación y estado analizados en Alba-Salas (2016a). 
de regularidad y transparencia; y la nivelación de paradigmas, que privilegia las formas más frecuentes en el input, esto es, aquellos rasgos usados por el máximo número de hablantes (Penny 2000: 40-42, Tuten 2003: 42-46). ${ }^{38}$ Es posible, pues, que los procesos de nivelación y simplificación asociados con la koiné de Madrid hubiesen favorecido la victoria de $V$-le $N$ porque esta Construcción habría sido más frecuente en el input, al aparecer en más ocurrencias y con muchos más sustantivos, y porque, como ya sabemos, mantuvo no solo una semántica transparente y composicional, sino también una forma más simple, sin alternancias preposicionales.

Además de ilustrar el efecto de dos procesos que parecen haber dado forma al español del XVI y el XVII, la victoria de $V$-le $N$ sobre el subesquema intencional ejemplificaría el resultado típico de la competencia entre Construcciones que codifican el mismo significado. En efecto, la obsolescencia de un (sub)esquema suele obedecer a la expansión de otro (sub)esquema sinónimo (Bybee 2015: 175-177). El (sub)esquema con la frecuencia de tipos más alta atrae progresivamente a los miembros de su competidor, sobre todo si este manifiesta un bajo grado de coherencia entre las micro-Construcciones que lo integran. Al principio, ambos (sub) esquemas se usan de forma intercambiable, pero con el tiempo el (sub) esquema con mayor productividad y coherencia interna reemplaza al otro, porque ya no interpretamos sus ocurrencias como parte de un patrón generalizable (Barðdal y Gildea 2015: 37-41). Sin embargo, a veces el (sub)esquema perdedor sobrevive en expresiones con un significado más especializado (Barðdal y Gildea 2015: 38-39). Esto ayudaría a explicar por qué se han conservado venirle en gana(s) y otras expresiones similares de uso marginal ${ }^{39}$.

38 Según Penny (2000: 37-42 y 63-68) y Tuten (2003: 50-58), una situación de koiné favorece el cambio lingüístico porque implica redes sociales débiles y porque los inmigrantes evitan los rasgos que los marcan como diferentes y adaptan su producción a la de otros hablantes. Esta acomodación privilegia no solo las formas más simples y más frecuentes en el input, sino también las que usan hablantes considerados particularmente prestigiosos.

39 Bybee (2015: 175-177) y Barðdal y Gildea (2015: 38-39) observan que en los casos típicos de competencia construccional, el (sub)esquema vencedor suele ser de creación más reciente. Lo mismo parece haber ocurrido con $V$-le $N$ y el subesquema intencional. Aunque ambos subesquemas se documentan desde los primeros textos, una observación apunta a que este último sea más antiguo: que en los antecedentes latinos de las colocaciones con entrar y venir el sustantivo de estado aparentemente ocurría con más frecuencia como objeto de la preposición IN 'en' (como en el subesquema intencional) que como sujeto gramatical (la estructura de V-le N; véanse Alba-Salas 2016a, 2016b y 2017). 


\section{CONCLUSIONES}

Al parecer, las colocaciones tipo venirle en voluntad -entendidas como un subesquema construccional que resultó particularmente productivo con venir, pero no con entrar ni, sobre todo caer-gozaron de cierta vitalidad en el Medievo, pero cayeron en desuso y se lexicalizaron en el XVI y el XVII, dejándonos solo reliquias fosilizadas como venirle en gana(s) (en todos los dialectos), y caerle/entrarle en gana, venirle en/(de) gusto y venirle en mente (estas últimas con un uso marginal únicamente en ciertas variedades).

La pérdida del subesquema de 'intención' obedecería a dos cambios relacionados que habrían tenido lugar fundamentalmente en el Siglo de Oro, combinación por combinación: la construccionalización léxica de dicho subesquema, y su obsolescencia. Este último cambio habría sido el resultado de la competencia con el subesquema sinónimo venirle/entrarle $N$, favorecido por su mayor productividad, transparencia semántica y coherencia interna. La construccionalización léxica del subesquema de 'intención' habría tenido lugar a través de reanálisis graduales tanto de su forma como de su significado. El desencadenante del reanálisis semántico habría sido la desaparición de la CVA haber/tener en/(a) $N$, que habría determinado la pérdida del sentido composicional del subesquema de 'intención' ('empezar a sentir $N_{\text {intención/deseo, }}($ de hacer algo)') y su reinterpretación estativa como 'apetecerle o antojársele' (esto es, 'sentir $N_{\text {intención/deseo }}$ (de hacer algo)') que tiene el venirle en gana(s) moderno. Solo dos combinaciones (venirle al pensamiento, ya desaparecida, y venirle a la/en mente, que aún se atestigua marginalmente con en) mantuvieron un sentido ingresivo con infinitivos, pero ya sin estar asociadas inherentemente con la 'intención de hacer algo', sino como parte de su uso más general como 'ocurrírsele (algo)' con complementos nominales. En todo caso, la pérdida de composicionalidad semántica del subesquema de 'intención' llevó al reanálisis del sintagma preposicional en que aparecía el nombre de 'intención' o 'deseo' como una secuencia fija. 


\section{REFERENCIAS BIBLIOGRÁFICAS}

\section{BASES DE DATOS}

CdE: Davies, Mark. 2002-. Corpus del Español (Histórico/Géneros y Web/Dialectos) [en línea]. Disponible en http://www.corpusdelespanol.org [Consulta: 2-3/2018].

CORDE: Real Academia Española. Corpus diacrónico del español (CORDE) [en línea]. Disponible en http://www.rae.es [Consulta: 2-4/2018].

CTILC: Institut D'Estudis Catalans. 2010-. Corpus Textual Informatitzat de la Llengua Catalana [en línea]. Disponible en http://ctilc.iec.cat/ [Consulta: 4/2018].

Loeb: Loeb, James, y Jeffrey Henderson. 1911-. Digital Loeb Classical Library. Harvard University Press [en línea]. Disponible en http://www-loebclassics-com [Consulta: 5/2018]

\section{BIBLIOGRAFÍA}

Alba-Salas, Josep. 2016a. Caer en temores infundados: Sobre la evolución histórica de las colocaciones con caer y sustantivos estativos. Revista de Historia de la Lengua Española 11: 3-30.

2016b. El triunfo del experimentador dativo: Las colocaciones con 'entrar + nombre de estado' en diacronía. Revista de Filología Española 96: 9-38.

2017. Venir vergüenza: Cambios históricos en las colocaciones con venir. Zeitschrift für romanische Philologie 133: 115-140.

2019 (en prensa). Caerle/venirle/(entrarle) en $N_{\text {agrado }}$ : Sobre el origen y la expansión de un subesquema construccional obsoleto. Scriptum Digital 8.

2020 (en prensa). Construccionalización y obsolescencia en las colocaciones tipo caerle/ venirle/(entrarle) en $N_{\text {agrado. }}$. Revista de Filología Española 100.

Alonso Ramos, Margarita. 2004. Las construcciones con verbo de apoyo. Madrid: Visor Libros.

BarĐDal, Jóhanna, y SpiKe Gildea. 2015. Diachronic Construction Grammar: Epistemological Context, Basic Assumptions and Historical Implications. En Jóhanna Barðdal, Elena Smirnova, Lotte Sommerer, y Spike Gildea (eds.). Diachronic Construction Grammar, pp. 1-49. Amsterdam: John Benjamins.

Barødal, Jóhanna, Elena Smirnova, Lotte Sommerer, y Spike Gildea (eds.). 2015. Diachronic Construction Grammar. Amsterdam: John Benjamins.

BARRAJón LóPez, Elisa. 2006. Análisis contrastivo locativo-nocional de la complementación de régimen verbal en el español hablado en Alicante: usos espaciales y abstractos de salir y entrar. Tesis doctoral, Universidad de Alicante.

Bosque, Ignacio. 2001. Sobre el concepto de ‘colocación' y sus límites. LEA: Lingüística Española Actual 23: 9-40.

Brinton, Laurel J. y Elizabeth Closs Traugott. 2005. Lexicalization and Language Change. Cambridge: Cambridge University Press.

Bustos Plaza, Alberto. 2005. Combinaciones verbonominales y lexicalización. Frankfurt: Peter Lang.

Bybee, Joan. 2015. Language Change. Cambridge: Cambridge University Press.

CANo Aguilar, Rafael. 1977. Cambios en la construcción de los verbos en castellano medieval. Archivum 27-28: 335-379. 
DCPEC: Bosque, Ignacio (ed.). 2006. Diccionario combinatorio práctico del español contemporáneo. Madrid: SM.

DCECH: Corominas, Joan, y José Antonio Pascual. 1980-1991. Diccionario crítico etimológico castellano e hispánico [CD Rom]. Madrid: Gredos.

DEA: Seco, Manuel, Olimpia Andrés y Gabino Ramos (eds.). 2012. Diccionario del español actual, $2^{\text {a }}$ ed. Madrid: Aguilar.

De Miguel, Elena. 1999. El aspecto léxico. En Ignacio Bosque y Violeta Demonte (eds.). Gramática descriptiva de la lengua española, vol. 2, pp. 2977-3060. Madrid: Espasa.

DiEC2: Institut D’Estudis Catalans. 2007-. Diccionari de la llengua catalana, $2^{\mathrm{a}}$ ed. [en línea]. Disponible en https://dlc.iec.cat/ [Consulta: 4/2018].

DRAE: Real Academia Española. 2015. Diccionario de la lengua española, 23 ${ }^{\mathrm{a}}$ ed. Madrid: Espasa-Calpe [en línea]. Disponible en http://dle.rae.es/ [Consulta: 1-3/2018].

Dubský, Josef. 1963. Formas descompuestas en el español antiguo. Revista de Filología Española 46: 31-48.

DUE: Moliner, María. 2002. Diccionario de uso del español [CD Rom, versión 2.0]. Madrid: Gredos.

FERnÁNDEZ-OrdóÑEZ, InÉs. 2002. Tras la collatio, o cómo establecer correctamente el error textual. La Corónica 30: 105-180.

Fried, MirJam. 2013. Principles of Constructional Change. En Thomas Hoffmann y Graeme Trousdale (eds.). The Oxford Handbook of Construction Grammar, pp. 419-437. Nueva York: Oxford University Press.

Glare, Peter G. W. (ed.). 1996. Oxford Latin Dictionary. Nueva York: Oxford University Press.

Goldberg, Adele E. 1995. Constructions: A Construction Grammar Approach to Argument Structure. Chicago: Chicago University Press.

2006. Constructions at Work: The Nature of Generalization in Language. Oxford: Oxford University Press.

2013. Constructionist Approaches. En Thomas Hoffmann y Graeme Trousdale (eds.). The Oxford Handbook of Construction Grammar, pp. 15-31. Nueva York: Oxford University Press.

Granvik, Anton. 2007. De como marca de infinitivo en el español antiguo. Interlingüistica 18: $564-574$.

Hoffmann, Thomas, y Graeme Trousdale (eds.). 2013. The Oxford Handbook of Construction Grammar. Nueva York: Oxford University Press.

LAPESA, RAFAEL. 1981. Historia de la lengua española, 9 ed. Madrid: Gredos.

1996. Crisis históricas y crisis de la lengua española. Madrid: Real Academia de la Historia.

Lehman, Christian. 2002. New Reflections on Grammaticalization and Lexicalization. En Ilse Wischer y Gabriele Diewald (eds.). New Reflections on Grammaticalization, pp. 1-18. Amsterdam: John Benjamins.

Lewis, Charlton T., y Charles Short. 1879. A Latin Dictionary. Oxford: Clarendon Press [en línea]. Disponible en http://www.perseus.tufts.edu/hopper/ [Consulta: 2/2018].

Martínez García, Hortensia. 2012. Viejos y nuevos valores de las preposiciones españolas. Verba 39: 7-34.

Melis, Chantal. 2018. Spanish Indexing DOM, Topicality, and the Case Hierarchy. En Ilia A. Seržant y Alena Witzlack-Makarevich (eds.). Diachrony of Differential Argument Marking, pp. 97-127. Berlín: Language Science Press.

Morera Pérez, Marcial. 1988. Estructura semántica del sistema preposicional del español moderno y sus campos de usos. Puerto del Rosario: Servicio de Publicaciones del Cabildo Insular de Fuerteventura. 
Morimoto, Yuko. 2001. Los verbos de movimiento. Madrid: Visor.

Nunberg, Geoffrey, Ivan A. Sag, y Thomas Wasow. 1994. Idioms. Language 70: 491-538.

Paz Afonso, Ana. 2013. Entrar en batalla: Aproximación a las relaciones léxicas entre el verbo entrar y el léxico del siglo XIII. En Emili Casanova y Cesáreo Calvo (eds.). Actes du XXVIe Congrès International de Linguistique et de Philologie Romanes, pp. 327-337. Berlin: Mouton de Gruyter.

Penny, Ralph. 2000. Variation and Change in Spanish. Cambridge: Cambridge University Press.

Pensado, Carmen. 1993. El ensordecimiento castellano: ¿Un fenómeno extraordinario? Anuario de Lingüistica Hispánica 9: 195-225.

PhiloBiblon: Faulhaber, Charles B., Arthur L-F. Askins, Harvey L. Sharrer y John G. May. 1997-. PhiloBiblon [en línea]. Disponible en http://bancroft.berkeley.edu/philobiblon/ search_en.html [Consulta: 2-6/2018].

REDES: Bosque, Ignacio (ed.). 2008. REDES: Diccionario combinatorio del español contemporáneo, $2^{\mathrm{a}}$ ed. Madrid: SM.

Rodríguez Molina, Javier, y Álvaro Octavio de Toledo y Huerta. 2017. La imprescindible distinción entre texto y testimonio: El CORDE y los criterios de fiabilidad lingüística. Scriptum Digital 6: 5-68. Base de datos CORDEMÁFORO [en línea]. Disponible en http://www.raco.cat/index.php/scriptumdigital/article/view/329259 [Consulta: 1-4/2018]

Serradilla CASTAÑo, ANA. 2011. Apuntes sobre fraseología histórica: Las expresiones figuradas con verbos de movimiento en español medieval. Círculo de Lingüistica Aplicada a la Comunicación 45: 21-54.

Traugott, Elizabeth Closs, y Graeme Trousdale. 2013. Constructionalization and Constructional Changes. Oxford: Oxford University Press.

Tuten, Donald M. 2003. Koineization in Medieval Spanish. Nueva York: Mouton de Gruyter. WulfF, Stefanie. 2013. Words and Idioms. En Hoffmann y Trousdale (eds.). The Oxford Handbook of Construction Grammar, pp. 274-289. Nueva York: Oxford University Press. 